\title{
INSIGHTS
}

\section{Family reflections: Make-A-Wish America}

\author{
Tiffany Loren Rowe ${ }^{1}$ \\ Pediatric Research (2019) 85:590; https://doi.org/10.1038/s41390-019-0297-8
}

I would love to begin by expressing my gratitude to Dr. Anup Patel and his team at Nationwide Children's for their personal and clinical interest in measuring the impact of a wish. Wish kids and their families have been sharing the power of wishes in their own lives since the day of Make-A-Wish's founding and this study is an incredible affirmation of a very human truth-hope can change lives. Thirty years ago, my wish inspired me to believe in my own future and the Make-A-Wish mission continues to bless my life every single day. It is an honor to share my story with you.

On Halloween night in 1984, I went to bed expecting to be with my classmates in the lunchroom the next day, trading candy and telling stories. In the next room, my mom was awake all night anticipating what we would learn at my annual check-up about why I had grown so pale, exhausted, and deeply bruised. I had my blood drawn in the morning on 1 November and by that afternoon my pediatrician was explaining that the results were inconclusive, but my condition was severe enough that he had arranged emergency transport from eastern Washington to Seattle. We were given $3 \mathrm{~h}$ to go home, pack, and say goodbye to friends and family. I arrived at Seattle Children's Hospital that evening by helicopter and just 2 weeks before my 12th birthday, childhood as I knew it was gone.

Within $48 \mathrm{~h}$, I was diagnosed with Severe Idiopathic Aplastic Anemia and because of the severity of my condition and the lack of a strong match, I was not a candidate for bone marrow transplant. We were offered the option of enrolling in what was then an experimental equine anti-thymocyte globulin protocol with methylprednisolone through Fred Hutch-my poor odds of survival were only slightly greater with treatment than without it. There was no viable alternative and, as the treatment progressed, and my body began to fail, my doctors prepared my family for the worst. The next few years held excruciating inpatient and outpatient treatments, failed remissions, unwavering dedication from my medical team, and my community's refusal to give up. We were in a race against time and my own body's natural defenses.

In early 1988 , I was a few months out of treatment for a relapse and progress was slow and uncertain. Then, on an otherwise unremarkable afternoon, the doorbell rang....and two Make-AWish volunteers asked me to trust them with my greatest wish when I had trouble trusting that I would see the end of the week. Nevertheless, something about being asked to dream brought a powerful light into the darkness and doubt and I wished to meet Michael Jackson. My childhood dream was to be a professional dancer and my love for Michael went well beyond the popularity of his music. Like me, dance was the way he felt most connected to the world and the power of his performances was inspirational to me throughout my treatment.
Underneath the courage that it required to stay focused on recovery, I was scared and very, very tired. But not on 20 April 1988. On that day, I was just a 15-year-old girl waiting breathlessly outside of Michael's green room at his Bad Tour concert stop in Chicago. We spent time together before he went onstage, and he was warm, kind, humble, and compassionate. And later, when he surprised me with an invitation to join him onstage during the song "Bad", I felt no fear, no exhaustion, no pragmatism-just pure joy. A joy that can transform a life. How do I know? Because I am a 46-year-old wish child.

For a long time, I had understandably been focused on day to day survival, but it was my wish that ultimately gave me the courage to believe in my future again, regardless of how many years that future would hold. Against all odds, my six-month prognosis stretched into a year and then to five years and ten. I graduated from high school and college, started a career, married my best friend, became a mother to two beautiful children through adoption, and tripled my life expectancy. When Make-AWish came into my life, all of these milestones felt impossible. And then Michael Jackson put his arm around my shoulder.

I returned home from Chicago and started reaching for my life again. Not because I was sure of my future, but because I was sure of my desire to fully live it. My wish reminded me that being sick did not define me; I was my own person before I was diagnosed and I could still shine through the shadow of my illness. The entire experience also started to teach me that I did not need to know how everything would turn out-just that I wanted to give every day my best. It gave me permission to let joy coexist with the fear and it made me braver than I had ever felt.

The Patel study is just the beginning of what I hope will be an area for further research in an effort to understand the relationship between a wish and a child's health outcomes. As a former pediatric patient and the parent of two young children, I am encouraged by the potential for applying these findings for powerful public good. As a wish child, I am eager for additional research to offer even greater opportunity for medical outreach and increased referrals for eligible children. It will be time and effort well spent.

Here is what I know in my bones about the impact of a wish from my own experience on that incredible day with Michael Jackson and every day since; a wish offers something entirely unique to children who are facing indescribable fear by creating a safe space for them to draw strength and resilience from the hopefulness and forgotten innocence of their childhood. A powerful memory they can return to for hope and inspiration throughout their lives. My wish did that for me. I believe it is an integral part of why I am here to write this letter today. Every wish is a life transformed.

${ }^{1}$ Kentfield, CA, USA

Correspondence: Tiffany Loren Rowe (info@pedres.org)

Received: 10 January 2019 Accepted: 10 January 2019

Published online: 21 January 2019 